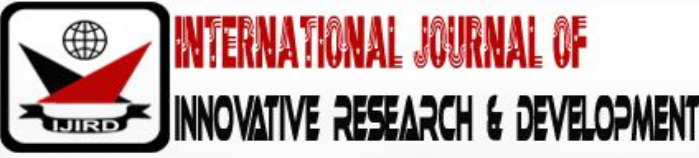

ISSN 2278 - 0211 (Online)

\section{Empirical Estimation of Monthly Average Daily Solar Radiation and Solar Electricity Output from Sunshine Hours in Ogoja in Nigeria}

\author{
Peter O. Ohiero \\ Lecturer, Department of Electrical and Electronic Engineering, \\ Cross River University of Technology, Calabar, Nigeria \\ Lawrence 0. Ogbeche \\ Lecturer, Department of Electrical and Electronic Engineering, \\ Cross River University of Technology, Calabar, Nigeria
}

\begin{abstract}
:
This paper presents an estimation of the monthly average daily global solar radiation for Ogoja from sunshine hours using Angrom-Prescott sunshine-based model. The solar photovoltaic power and energy output were also estimated from the solar radiation. The monthly average daily extra-terrestrial radiation was estimated and used with the sunshine hour's data obtained from the Nigeria Meteorological Agency, (NIMET), Margaret EKPO International Airport, Calabar, Nigeria to estimate the monthly average daily global solar radiation for a period of five years (2012-2017). The results show a variation of solar radiation with sunshine hour, season of the year with higher solar radiation in the dry season with the highest value of $22.34 \mathrm{MJ} / \mathrm{m} 2 /$ day in the month of April and lower in rainy season with the least value of $16.27 \mathrm{MJ} / \mathrm{m} 2 /$ day in the month of July. The results also show that about 4.56MWh can be produce per day using 2453 solar PV panels of area $1.65 \mathrm{~m}^{2}$ each in an acre of land. These results have provided a data base of monthly average daily global solar radiation for Ogoja and have shown that Ogoja is suitable for the installation of solar PV for the generation of electric power and use for other applications.
\end{abstract}

Keywords: Sunshine hours, global solar radiation, solar energy system, solar electricity

\section{Introduction}

Recent economic and fuel crisis in Nigeria opened a wider opportunity for renewable energy resources. The federal government of Nigeria has proposed to generate 30GW of installed on-grid electricity by the year 2030 of which $30 \%$ of total energy capacity will be obtain from renewable energy resources ((NREAP, 2016). Among the renewable energy sources, solar energy has the largest source and greater potential to meet this target. The solar energy is from the sun, it is a natural, free and environmentally friendly source of energy and can be harnessed using appropriate technology to generate electricity and use for other applications. However, the availability of solar radiation depends on the geographical location and latitude on the surface of the earth.

Nigeria lies in the high solar radiation belt with an average solar irradiation of $2011 \mathrm{kWh} / \mathrm{m} 2$ per year with the northern part having greater potentials with a horizontal irradiation of $7 \mathrm{kWh} / \mathrm{m} 2$ per day suitable for large-scale solar photo voltaic (PV) electricity or solar thermal electricity project. The southern part also has a horizontal solar irradiation of $4 \mathrm{kWh} / \mathrm{m} 2$ per day suitable for on-grid and off-grid small scale solar project for residential, social, commercial and cottage industrial use. In order to achieve this there is need for aggressive deployment of solar PV electricity across the country. However, not every location on the earth's surface has the required solar radiation to generate electric energy. Therefore, knowing the solar radiation data at a particular location is important in knowing the amount of electric energy that can be harnessed, the design and development of the type of solar energy conversion technologies that can be deployed.

Solar radiation is measured hourly at weather stations using equipment such as Pyrheliometer and pyranometer and this help us to know the daily, weekly, monthly, annual solar radiation, and average solar radiation on the horizontal earth surface. This equipment measures both the direct and diffused components of solar radiation and give their sum which is the global solar radiation. These parameters are measured over time and the average values calculated. In developing countries 
and most part of the world, weather stations are absent and where there are available, the measured values of solar radiation are scare and, in some cases, there are totally absent. Where the measured values are available, they can be used directly, where their values are not available, they are estimated using available measured parameters such as sunshine hours and temperature, precipitation, relative humidity, effect of cloudiness, soil temperature, evaporation, reflection of the locality, etc. using theoretical or empirical models. There are a number of empirical models and methods that can be used to estimate the daily or monthly global solar radiation. The accuracy of these models in estimating the monthly global daily solar radiation against the measured values as well as their statistical performance and correlation have been studied by several researchers (N. N. Gana et al., 2014; Girma Dejene Nage, 2018; M. N. Nnabuchi et al., 2013). Some of these empirical models have been used to estimate global solar radiation for some parts of Nigeria but Ogoja is yet to have a solar radiation data base. Accurate solar radiation data can be used as input to modelling, design, evaluation of performance and analysis of solar power generation system, hybrid renewable-fossil fuel power system optimisation using HOMER, etc. (Getachew Bekelea, et al., 2012; Getnet Zewde Somano, et al., 2016); B.U. Musa, et al., 2015). In addition, a comprehensive solar radiation data is required in all locations in the country.

This paper's objective is to estimate the monthly average daily global solar radiation on the horizontal surface from sunshine hours at Ogoja and to estimate the amount of solar power and energy output that can be generated per square area in this location.

\subsection{Estimation of Monthly Average Daily Global Solar Radiation}

There are many empirical models that have been used to estimate monthly daily average solar radiation. The most widely used are the sunshine and temperature based empirical model.-These empirical models, takes into considerations factors that influence the value of solar radiation such as latitude, longitude, elevation of the location, solar constant, earth-sun distance, solar declination and hour angle, extra-terrestrial solar radiation, azimuth angle of the surface, tilt angle of the surface, sun elevation angle, sun azimuth angle, presence of scattered fair molecules, water vapour, scattered dust and atmospheric gasses e.g. $\mathrm{O}_{2}, \mathrm{CO}_{2}$, etc.

\subsection{Sunshine Based Models}

Since measured sunshine hours are available for Ogoja, the Angstrom-Prescott model was used to estimate the horizontal global solar radiation for Ogoja. The model is given by;

$$
\begin{array}{ll}
\frac{\mathrm{H}}{\mathrm{H}_{0}}=\mathrm{a}+\mathrm{b} \frac{\mathrm{s}}{\mathrm{s}_{0}} & 1 \\
\mathrm{H}=\mathrm{H}_{0}\left(\mathrm{a}+\mathrm{b} \frac{\mathrm{s}}{\mathrm{s}_{0}}\right) & 2
\end{array}
$$

Where $\mathrm{H}$ is the monthly average daily global solar radiation, $\mathrm{H}_{0}$ is the monthly average daily extraterrestial radiation, $\mathrm{S}$ is the monthly average daily hours of bright sunshine ( $\mathrm{hr}$ ), $\mathrm{S}_{0}$ is the monthly average daily maximum hours of possible sunshine (hr), $\mathrm{a}$ and $\mathrm{b}$ are empirical or regression coefficients of the Angstrom-Prescott model. The empirical or regression coefficient a and $\mathrm{b}$ are calculated from the relationship given as ((N. N. Gana et al., 2014);

$$
\begin{array}{ll}
\mathrm{a}=-0.110+0.235 \cos \emptyset+0.323\left(\frac{\mathrm{s}}{\mathrm{s}_{0}}\right) & 3 \\
\mathrm{~b}=1.449-0.553 \cos \emptyset+0.694\left(\frac{\mathrm{s}}{\mathrm{s}_{0}}\right) & 4
\end{array}
$$

One of the key factors for the estimation of monthly average daily global radiation is the daily average extraterrestrial radiation on the horizontal surface $\left(\mathrm{H}_{0}\right)$ given by;

$\mathrm{H}_{0}=\frac{24 \times 3600}{\pi} \mathrm{I}_{\mathrm{sc}} *\left(1.0+0.033 * \cos \left(\frac{360 \mathrm{dn}}{365}\right)\right) *\left(\cos \emptyset \cos \delta \sin \omega_{\mathrm{s}}+\frac{\pi}{180} \omega_{\mathrm{s}} \sin \delta \sin \emptyset\right) \quad 5$

Where: $\mathrm{H}_{0}$ is the daily average extraterrestial radiation on the horizontal surface (MJ/ $\mathrm{m}^{2}$ day), $\mathrm{I}_{\mathrm{sc}}$ is the solar constant given as $1367 \mathrm{~W} / \mathrm{m}^{2}, \emptyset$ is the latitude of the location, dn is the number of days of the year starting from January 1 to December $31, \omega_{\mathrm{s}}$ is the mean sunset hour angle and $\delta$ is the solar declination angle. The solar declination angle $\delta$ and the mean sunset hour angle $\omega_{\mathrm{s}}$ can be computed using;

$$
\begin{array}{rlrl}
\delta & =23.45 \sin \left(\frac{360}{365}(284+\mathrm{dn})\right) & 6 \\
\omega_{\mathrm{s}} & =\cos ^{-1}(-\tan \emptyset \tan \delta), \text { while } \mathrm{s}_{0}=\frac{2}{15} \omega_{\mathrm{s}} & \\
\text { and } \mathrm{s}_{0} & =\frac{2}{15} \omega_{\mathrm{s}} & & 8
\end{array}
$$




\subsection{Solar Electricity Output}

Electrical energy is generated from sunlight using photovoltaic (PV). Solar PV panel output can be calculated for a day, a month, a year and per square metre. The output of solar panel depends on the amount of sunshine it receives from the sun, the period of the day, the orientation of the panels and the season of the year. In a day, solar panel generates less amount of power in the morning and evening than in the afternoon. This variation in the output is taken care of in the estimation of the solar irradiation and solar radiation. The output of solar panel is the amount of electricity produced by solar panel over time in watt-hour. It can be calculated from the solar irradiation and solar radiation. The total power of solar PV can produce is given by;

$$
\mathrm{P}=\mathrm{A} \times \mathrm{SI} \times \eta_{\mathrm{Con}}
$$

Where P the total power in Watts (W), A is the area of a solar PV panel or solar PV system in square metre $\left(\mathrm{m}^{2}\right)$, SI is the solar irradiance in Watt per square metre $\left(\mathrm{W} / \mathrm{m}^{2}\right)$ and $\eta_{\text {Con }}$ is the conversion efficiency $(\%)$. The solar irradiance for a surface perpendicular to the sun's rays at sea level on a clear day is about $1000 \mathrm{Watts} / \mathrm{m}^{2}$.

Solar PV produces electricity over time measured in watt-hour (Wh). The amount of energy solar PV produces in a day is given by;

$$
\mathrm{E}=\mathrm{A} \times \mathrm{H} \times \eta_{\mathrm{Con}}
$$

Where E the total energy output in $\mathrm{kWh} /$ day, $\mathrm{A}$ is the square area of solar PV system in square metre $\left(\mathrm{m}^{2}\right), \mathrm{H}$ is the solar radiation in $\left(\mathrm{kWh} / \mathrm{m}^{2} /\right.$ day) and $\eta_{\text {con }}$ is the conversion efficiency (\%). These outputs can be calculated for a month and a year.

\subsection{Description of Location}

The location used in this study is Ogoja. It is located in the South but closer to the middle belt of Nigeria. It is located on latitude $6.30^{\circ} \mathrm{N}$ and longitude $8.40^{\circ} \mathrm{N}$ with an elevation of $128 \mathrm{~m}$ above sea level. It has an area of $972 \mathrm{Km}^{2}$ and a population of 171,574 in 2006 census and a projected population in 2016 of 229,300 .

\section{Methodology}

The daily average extra-terrestrial radiation on the horizontal surface, $\mathrm{H}_{0}\left(\mathrm{MJ} / \mathrm{m}^{2}\right.$ day) for each month were calculated. The measured sunshine hours for this location for five years (2012-2017) were obtain from Nigeria Meteorological Agency (NIMET) at Margaret Ekpo International Airport, Calabar. The average daily and monthly solar sunshine hours were computed and used to estimate the monthly average global solar radiation for Ogoja as shown in Table 1. From the results shown in Table 1, the solar electrical power and energy output for a Solar PV panel of area $1.65 \mathrm{~m}^{2}$ was calculated.

\section{Results and Discussion}

\subsection{Results}

\begin{tabular}{|c|c|c|c|c|c|c|c|c|c|c|}
\hline Month & $\mathbf{\omega}_{\mathbf{s}}(\mathbf{d e g})$ & $\mathbf{s}(\mathbf{h r})$ & $\mathbf{s}_{\mathbf{0}}(\mathbf{h r} \mathbf{r})$ & $\mathbf{S} / \mathbf{S o}$ & $\mathbf{a}$ & $\mathbf{b}$ & $\begin{array}{c}\mathbf{T}_{\mathbf{m a x}} \\
\mathbf{( 0 C )}\end{array}$ & $\begin{array}{c}\mathbf{T}_{\min } \\
\mathbf{( \mathbf { C } )}\end{array}$ & $\begin{array}{c}\text { Ho } \\
\mathbf{( M J m}^{-2} \mathbf{d a y}^{-1} \mathbf{)}\end{array}$ & $\begin{array}{c}\mathbf{H} \\
\mathbf{( M J m}^{-2} \mathbf{d a y}^{-\mathbf{1}} \mathbf{)}\end{array}$ \\
\hline Jan & 87.60 & 6.9 & 11.7 & 0.59 & 0.31 & 0.49 & 26.11 & 19.28 & 33.97 & 20.49 \\
\hline Feb & 88.58 & 7.1 & 11.8 & 0.60 & 0.32 & 0.48 & 28.22 & 21.67 & 36.56 & 22.22 \\
\hline Mar & 89.73 & 6.3 & 12.0 & 0.53 & 0.29 & 0.54 & 29.00 & 23.33 & 38.2 & 21.93 \\
\hline Apr & 91.09 & 6.5 & 12.1 & 0.54 & 0.30 & 0.53 & 28.72 & 23.5 & 38.52 & 22.34 \\
\hline May & 92.15 & 6.4 & 12.3 & 0.52 & 0.29 & 0.54 & 27.28 & 22.78 & 37.52 & 21.45 \\
\hline Jun & 92.71 & 5.4 & 12.4 & 0.44 & 0.26 & 0.60 & 26.39 & 22.28 & 36.66 & 19.22 \\
\hline Jul & 92.45 & 3.9 & 12.3 & 0.32 & 0.23 & 0.68 & 25.50 & 21.94 & 36.87 & 16.27 \\
\hline Aug & 91.55 & 3.7 & 12.2 & 0.30 & 0.22 & 0.69 & 25.50 & 21.94 & 37.84 & 16.29 \\
\hline Sep & 90.11 & 4.4 & 12.0 & 0.37 & 0.24 & 0.64 & 25.78 & 21.78 & 38.16 & 18.26 \\
\hline Oct & 88.9 & 5.7 & 11.9 & 0.48 & 0.28 & 0.57 & 26.39 & 21.94 & 36.96 & 20.32 \\
\hline Nov & 87.80 & 7.4 & 11.7 & 0.63 & 0.33 & 0.46 & 26.50 & 20.89 & 34.88 & 21.59 \\
\hline Dec & 87.29 & 7.4 & 11.6 & 0.64 & 0.33 & 0.46 & 25.72 & 19.06 & 33.66 & 20.90 \\
\hline
\end{tabular}

Table 1: Monthly Average Values of Daily Solar Radiation for Ogoja of 2012 To 2017 


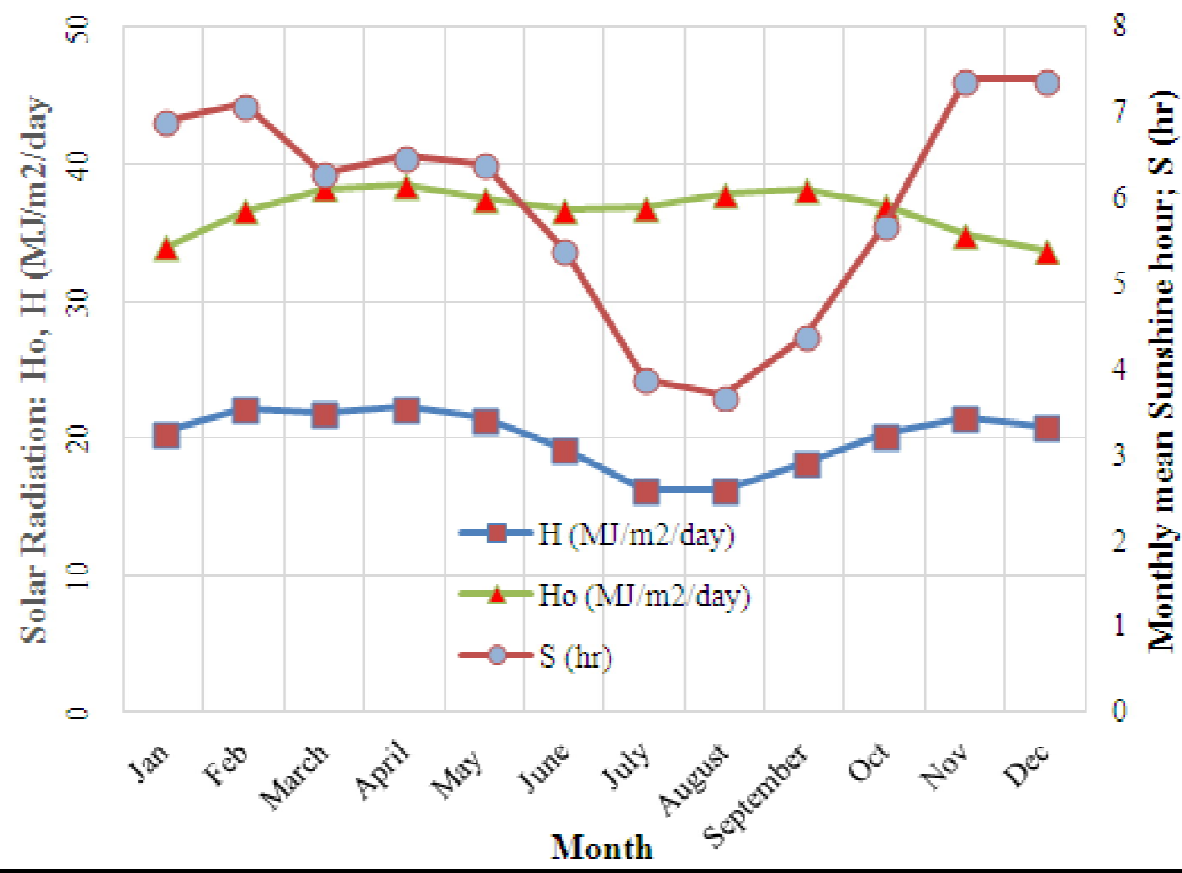

Figure 1: Monthly Average Daily Global Solar Radiation (H), Extra-Terrestrial Solar Radiation (Ho) and Sunshine Hour (S)

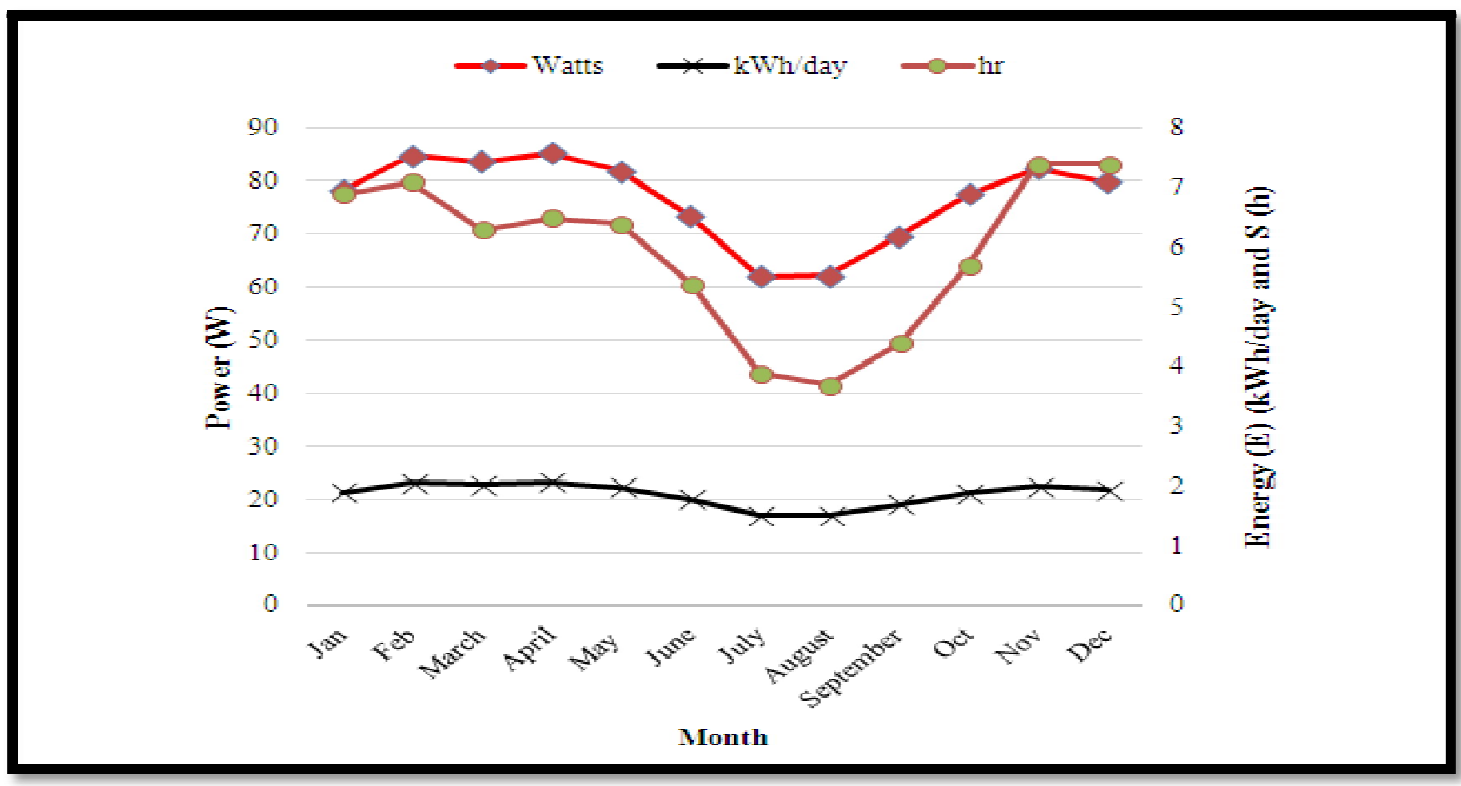

Figure 2: Monthly Average Solar Electrical Power and Energy for One Solar PV of Area, $1.65 \mathrm{~m}^{2}$

Figure 1 shows the estimated monthly average daily global solar radiation on a horizontal surface of Ogoja for the period of five years (2012 - 2017). It can be seen that the earth surface at Ogoja receives high global solar radiation for seven months of the year from February to May and October to December with a monthly average daily global solar radiation of $20.16 \mathrm{MJ} / \mathrm{m}^{2} /$ day. This is a huge potential for solar electricity generation. Figure 2 shows the estimated solar electrical power and energy output of a 250Wp solar PV panel with an area of $1.65 \mathrm{~m}^{2}$ and a conversion efficiency of $20 \%$ from the average daily solar radiation and solar irradiance. It can be seen that the energy that can be produced by one solar PV panel per day in the month of February, March, April and May are 2.05kWh/ day, 2.03kWh/ day, $2.06 \mathrm{kWh} /$ day and $1.98 \mathrm{kWh} /$ day respectively. And in the month of October, November and December, the values are $1.88 \mathrm{kWh} /$ day, $2.0 \mathrm{kWh} /$ day and $1.93 \mathrm{kWh} /$ day respectively with a monthly average daily solar electrical energy of $1.86 \mathrm{kWh} /$ day. These values of power and energy output per day can be multiplied by increasing the solar power systems area and numbers of solar panels. For example, an acre of land which is $4046.86 \mathrm{~m}^{2}$ will have $4046.86 \mathrm{~m}^{2} / 1.65 \mathrm{~m}^{2}=2453$ solar PV panels and can produce $2453 \times 1.86 \mathrm{kWh} /$ day $=$ 4.56MWh/ day. This is the monthly average daily solar electrical energy output of a solar PV system with 2453 solar PV panels 
in an acre of land. This value can be multiplied by 30 days or 365 days to know the energy that can be produced by one acre of flat, shadeless land in Ogoja for a month and year respectively.

\section{Conclusion}

The monthly average daily global solar radiation, solar PV electrical power and energy output has been estimated for Ogoja using the sunshine hours-based method. The results show a variation of solar radiation as the sunshine hour varies. The results also show a seasonal variation of solar radiation which is higher in the dry season with the highest value of $22.34 \mathrm{MJ} / \mathrm{m} 2 /$ day in the month of April and lower in rainy season with the least value of $16.27 \mathrm{MJ} / \mathrm{m} 2 /$ day in the month of July. The results show that Ogoja is suitable for the installation of solar PV for the generation of electric power. It is possible to generate $4.56 \mathrm{MWh} /$ day using 2453 solar PV panels of area $1.65 \mathrm{~m}^{2}$ each in an acre of land. These results have also provided a data base of monthly average daily global solar radiation for Ogoja.

\section{References}

i. [National Council on Power (NACOP), The Federal Republic of Nigeria (2016). National Renewable Energy Action Plans (NREAP) (2015-2030).

ii. N. N. Gana, Jitendra K. Rai and Musa Momoh (2014). Estimation of Global and Diffuse Solar Radiation for Kebbi, NorthWestern, Nigeria, International Journal of Scientific \& Engineering Research, Volume 5, Issue 1, pp. 1654 -1661.

iii. Girma Dejene Nage (2018). Estimation of Monthly Average Daily Solar Radiation from Meteorological Parameters: Sunshine Hours and Measured Temperature in Tepi, Ethiopia, International Journal of Energy and Environmental Science, 3(1): 19-26

iv. M. N. Nnabuchi, J. E. Ekpe and G. F Ibeh (2013). Estimation of Global Solar Radiation in Onitsha and Calabar Using Empirical Models, Communications in Applied Sciences, Volume 1, Number 1, 25-37.

v. Getachew Bekelea, Gelma Boneya (2012). Design of a Photovoltaic-Wind Hybrid Power Generation System for Ethiopian Remote Area, Energy Pocedia 14.1760 - 1765.

vi. Getnet Zewde Somano, Getachew Shunki (2016). Design and Modelling of Hybrid PV-Micro Hydro Power Generation Case Study Jimma Zone, American Journal of Electrical Power and Energy Systems, 5960; 91-98.

vii. B.U. Musa, Kalli .B. M, Sadiq. M.G and B.U. Tijjani (2015). Modeling and Analysis of Hybrid Solar/ Wind Power System for a Small Community, IOSR Journal of Electrical and Electronics Engineering (IOSR-JEEE) e-ISSN: 2278-1676, p-ISSN: 2320-3331, Volume 10, Issue 1 Ver. I, pp. 39-45. 